\title{
Once a Rebel, Now Settled
}

Seeing the stark contrast in realities from distant worlds

A foot in both and not knowing how to settle them

A voice in the wilderness rebelling against inequality

A soul torn apart

Settling in the midst of intellectuals

Who discuss minute points about things that don't matter to most of the world

We want to show how smart we are

Critique works we cannot do

Break down ideas to the point that they make no sense

Scheme to get ahead

How do I position myself for a Ph.D., for tenure, for full, to be an administrator?

At some point we forget the reason we came here

We came to be a voice for the voiceless, speaking our truth

To help those lost in words and theories see the reality of what they study

Who are the people we speak of and why is world categorized?

We generalize and ask meaningless questions that we cannot answer

With words only but no action

How do we move from the rut of our jobs?

The monotony of endless email and meaningless committee assignments

To remember the passion that brought us here

We are here for more than busy work

And the careerism that Black Studies creators warned us about

We are here with a platform to inform, reform, and revolutionize

To create global citizens with the potential to transform the world

In the midst of strengthening racism and xenophobia

We fight an uphill battle

But no harder than our ancestors have fought so many times before

Who are we?

Blessed with knowledge

Pondering the irrelevant

Working to death but building nothing

In awe of insignificance things

Burdened down by meaningless tasks

Lost from purpose

Hanging on a string on the verge of collapse

Wondering how we got here 
It's time to be unsettled and do the work which brings meaning Not as a rebel with no cause Or a follower of someone else's lead But as one who sees a path set before her And walks it with the grace of a person possessed with a mission To move beyond her career To do what transforms the important spaces around her Unsettle the rebel. 